in small and frequent doses, plentifully diluted with tepid water.

Practitioners of thirty years' standing can probably recollect -as I am sure that I can-the occurrence of cases of spasmodic cholera, treated with calomel and opium, exhibiting cold sur face, blue skin, and the most awful spasm, but from which recovery was the general rule. Such cases still occur in this ultima thule, and I doubt not elsewhere. The voice was also suppressed in severe cases of the old spasmodic cholera; and I remember with the utmost clearness how strongly the first sight of a rice-water evacuation in 1833 enabled me to distinguish that peculiar fluid from every other that I had ever seen emanate from the human body. Would it not be well, then, that the existence of this symptom should be the indispensable title of every case to be ranked as cholera, and that such symptom should be present in every case subjected to experimental treatment?

I should also be glad to see the day arrive when the profession will be less anxious to publish infallible remedies for approaching supposed cholera. Suppositious cases might be left to the apprentices, while their masters should be devising some remedy for the real and patent dangers of the rice-water stage and its immediate antecedents.

Helston, Aug. 185t

ON

\section{THE PRESERVATION OF THE HEALTH OF THE BRITISH SOLDIERS AND SAILORS, AND THAT OF OUR ALLIES.}

By J. H. TUCKER, EsQ.,

HONORARY SEORETARY TO THE EPIDEMTOLOGICAL SOCTETX.

Aт a time like the present, when our soldiers, as well as those of our allies, are, or have been, suffering from epidemic bowel complaints, cholera, dysentery, \&c., I hope I may be excused for suggesting, through your journal, the use of dilute sulphuric and nitric acids, or sulphuric acid alone, as a mean of prevention of cholera and dysentery.

In my paper, read before the Epidemiological Society on the 3rd of July, I alluded to these acids as prophylactics of cholera, and quoted Dr. Fergusson, who mentioned nitric acid as well as the juices of acid and sub-acid fruits, as preventive of dysentery.

It has been proved that in cider counties, where that drink is the common beverage, the inhabitants are in great degree exempt from epidemic bowel complaints; and Mr. Herapath, of Bristol, the analytical chemist, has shown that cider resembles sulphuric and nitric acids, with water, sugar, \&c. - See Tme LLANCET, August 2nd, 1851.

Sir Gilbert Blane, M.D., in his work "On the Diseases of Seamen," Dr. Fergusson, and others, have spoken of the value of vinegar, both amongst patients in the navy and army, as preventive and remedial of disease, and both allude to the use of this article by the ancient Romans as a means of the preservation of the health of their armies.

Dr. Bryson, R.N., recommends quinine and wine as a means of prevention of fever, \&c., but as these valuable articles cannot be rendered available, I presume, to our soldiers located where they are, and as the acids I have named can be, I hope I may not be deemed presumptuous in drawing attention to their efficacy. Dilute sulphuric and nitric acids, or sulphuric acid alone, in porter or ale, wonld not, I think, be objected to by our brave soldiers and those of our allies, especially when they understood the benefit to be derived from the recom. mendation of their medical officers.

Berners-street, August, 1854.

\section{SULPHATE OF BEBEERINE IN DIARRHEA.}

By WM. CLARENCE MATTHEWS, Esq., M.R.C.S.

At a time like the present, when our doors are besieged by patients labouring under severe attacks of diarrhoa, which, to say nothing of its being a premonitory symptom of that scourge, cholera, is in itself a dire malady, and will, as I can personally bear testimony, in the course of a few hours so reduce a patient as to render him almost unable to cross the room, - at a time like this it behoves us all to bring before the public anything which may occur to us as an antidote.

I am not aware that bebeerine has ever been extolled for it virtues as an astringent in this complaint. Remedies $I \mathrm{am}$ aware are numerous, and tolerably efficacious, but none have I found to supersede this, and I have used it extensively both this season and last. Something, I admit, may be due to its combination, but the following I find a very near approach to a specific, and that with very few doses, as a rule; indeed, in many instances its effects are magical, for in the course of half an hour I have seen a patient restored from intolerable anguish to perfect ease :- Sulphate of bebeerine, twelve grains; sulphuric acid and rectified ether, of each twelve minims; to six ounces of cinnamon-water; make a mixture, one ounce to be taken every four hours. I generally first give a pill consisting of two grains of calomel and half a grain of opium, and if there is great pain, or the vomiting is urgent, order a sinapism to the scrobiculus cordis, then follow up with the bebeerine mixture. In almost all cases of diarrhoa which fall under my care $I$ adopt this treatment, and in no instance has it failed.

Longsight, near Manchester, August, 1854.

TREATM ENT

OF

\section{CHOLERA AND DLARRHCEA}

$$
\text { IN THF }
$$

\section{VARIOUS HOSPITALS, INFIRMARIES, AND DIS- PENSARIES IN THE METROPOLIS.}

No. III.

WE are glad to say that since we closed the report inserted in the last number of this journal, the epidemic has not progressed with the gigantic strides with which it had advanced during the last four weeks; this is certainly a good sign, and we harbour the hope that a rapid decrease will soon take place. The alarm of the public mind is not of that distressing and lowering kind which is so unfavourable in trying times; the medical profession do their duty, sometimes under very painful circumstances, and the prospects are getting less gloomy.

Efforts are being made at home and abroad to improve the treatment, and new agents are being tried, with moderate success. Amongst these we should mention strychnine, which has now been extensively used in Paris, both in the form of simple alkaloid and the sulphate. It is M. Abeille who has principally extolled this remedy, which had already been used endermically at St. Petersburgh, in 1832 , by M. Dreyfus. Those practitioners who have followed M. Abeille's plan have not been quite so successful as the advocate of strychnine: we find, for instance, Mi. Hérard stating, in L'Union Médicale of the 26 th of August, that he has tried the remedy (the sulphate of strychnine) in twenty-four cases, thus subdivided:-fourteen very severe, seven severe, and three moderately so. The dose varied according to the severity of the cases, from the fifth of a grain to half a grain; and out of the fourteen patients of the first subdivision eleven died and three recovered. In the second, two recovered and one died; and as the four remaining ones became worse with the strychnine, they were given ipecacuanha, and got well. The three patients of the last division recovered, like all those, (says M. Hérard,) whose symptoms are not severe, whichever be the means employed.

So much for strychnine. Still practitioners should not therefore maintain, or allow it to be stated that no therapentical agents have any effect on cholera; the main point to be kept in view is the distinction between the stages. When a patient presents all the symptoms of the last stage, our art is powerless; but we would ask, as M. Richelot justly does, in the journal above quoted, "What effect have remedies in the third stage of pneurnonia?" How many patients recover with whom that stage becomes fully developed?

Sinapisms have been highly spoken of by M. Legroux, phy sician to the Hôtel Dieu, and his article in the Gazette $H e b$ domadaice seems to us extremely sensible. He states,-"We possess no direct action against the unknown cause of cholera; nor any remedy for this malady when fully developed. To combat the disease we have no weapons but those to be found in general therapeutics, and the treatment should therefore be based on the indications deduced from the principal phenomena, and the morbid changes which are taking place."

M. Legroux thinks we should principally promote reaction in opposition to the algid concentration, and do so by moderate means of calefaction. We should, in the first instance, do no

* We place the hospitals in each series from east to west. 